\title{
Hyperspectral cathodoluminescence imaging of modern and fossil carbonate shells
}

\author{
Jennifer England, ${ }^{1}$ Maggie Cusack, ${ }^{1}$ Niall W. Paterson, ${ }^{1}$ Paul Edwards, ${ }^{2}$ Martin R. Lee, ${ }^{1}$ \\ and Robert Martin ${ }^{2}$
}

Received 25 November 2005; revised 18 April 2006; accepted 25 April 2006; published 18 July 2006.

[1] Optical cathodoluminescence (CL) is commonly used to identify diagenetically altered carbonate fossils, yet such an interpretation is problematic as present-day carbonate shells may also luminesce. Hyperspectral CL imaging combines CL microscopy and CL spectroscopy to quantitatively analyze luminescence emission. Cold optical CL and hyperspectral CL imaging were carried out on four modern biominerals, a Rhynchonelliform brachiopod, a Craniid brachiopod, a bivalve, and the eggshell of the domestic fowl. A fossil Craniid brachiopod was analyzed to compare luminescence emission with that from the modern Craniid brachiopod. The beam conditions used for optical CL vary between studies, which hinders the direct comparison of CL analyses. This study assesses the effect of beam current and beam diameter on the intensity of luminescence emission. By characterizing the effect of beam conditions on different $\mathrm{CaCO}_{3}$ biominerals, comparisons can be made between CL studies. Hyperspectral CL imaging can be carried out in combination with WDS element analysis. By comparing hyperspectral CL images with element maps the causes of luminescence can to some extent be determined. The intensity of luminescence emitted from the modern biominerals differs under the same beam conditions. All four modern shells emit blue luminescence. In $N$. anomala, there is a correlation between $\mathrm{Mn}^{2+}$ concentration and luminescence intensity in the 620- to 630-nm wavelength band, which is apparent in the inner region of the shell. The fossil Craniid also emits blue luminescence, and texture within the shell wall is apparent; however, the luminescence emission between 620 and $630 \mathrm{~nm}$ that is evident in $N$. anomala is absent.

Citation: England, J., M. Cusack, N. W. Paterson, P. Edwards, M. R. Lee, and R. Martin (2006), Hyperspectral cathodoluminescence imaging of modern and fossil carbonate shells, J. Geophys. Res., 111, G03001, doi:10.1029/2005JG000144.

\section{Introduction}

[2] Fossil brachiopod and bivalve shells have been used in numerous studies of secular changes in the chemical and isotopic composition of the oceans throughout the Phanerozoic [e.g., Korte et al., 2003, 2005; Veizer et al., 1999; Stueber and Rauch, 2005]. In some cases, regions within these shells are secreted in chemical and isotopic equilibrium with ambient seawater and therefore may provide an accurate record of its chemistry and temperature at the time of growth [Auclair et al., 2003, Parkinson et al., 2005]. Ancient carbonate shells, however, are prone to recrystallization during diagenesis, which can modify their original chemical and isotopic composition, thus rendering the shell material unsuitable for palaeoceanographic studies. Optical CL has been employed as a screening technique to identify any diagenetically altered shell material [e.g., Czerniakowski et al., 1984; Popp et al., 1986; Middleton et

\footnotetext{
${ }^{1}$ Department of Geographical and Earth Sciences, University of Glasgow, Glasgow, UK.

${ }^{2}$ Department of Physics, University of Strathclyde, Glasgow, UK.

Copyright 2006 by the American Geophysical Union. 0148-0227/06/2005JG000144\$09.00
}

al., 1991; Barbin et al., 1991]. Luminescent shell material was previously assumed to have undergone diagenetic alteration and rejected in order to prevent the introduction of bias into the data sets.

[3] The assumed correlation between luminescence and alteration has been challenged by the discovery of presentday luminescent carbonate shells from neritic, pelagic and hydrothermal vent environments [Barbin, 1991, 1992; Barbin et al., 1991, 1995; Schein et al., 1991]. Rush and Chafetz [1990] have also stated that using CL to determine the state of alteration of brachiopod calcite is highly questionable, because its chemical and isotopic compositions can be modified without the shell becoming luminescent. Furthermore, Friedman [1993] used examples of present-day and Pleistocene reef carbonates from the Red Sea to propose that diagenesis can result in decreasing luminescence intensity.

[4] The consensus of most previous studies of luminescence in carbonate minerals is that intensities of the characteristic orange-red CL relate, in some manner, to the concentrations of $\mathrm{Mn}^{2+}$ (activator) and $\mathrm{Fe}^{2+}$ (quencher) [e.g., Sommer, 1972; Machel et al., 1991]. Despite the identification of the main activator and quencher elements, the relationship between luminescence intensity and calcite 
composition is still poorly understood. It is therefore of concern that, regardless of the controversy and uncertainties regarding the use of cathodoluminescence in the assessment of diagenetic alteration of fossil shells, it continues to be used for this purpose. It is clearly important that we gain a better understanding of the underlying causes of luminescence since CL is such a widely used technique [Samtleben et al., 2001; Banjeree and Habermann, 2000; Barbin, 1992].

[5] In addition to the debate regarding its use as an indicator of diagenesis in carbonate shells, the optical CL techniques that have been used to date have a number of disadvantages that impose severe limitations on their use in diagenetic studies. Conventional cold optical CL allows for limited control over the beam current conditions. This is a major drawback since the total luminosity emitted by carbonates is a function of a number of factors, which include the accelerating voltage and beam current applied. Even when controlled beam conditions are available, the fact that most studies use a different instrument and set of conditions hinders the direct comparison of previous studies. For example, Ramseyer et al. [1989] advocate the use of a (hot cathode) CL-microscope with a beam current density of $0.3 \mu \mathrm{A} / \mathrm{mm}^{2}$ at $30 \mathrm{keV}$ energy while Budd et al. [2000] used conditions of $\sim 380 \mathrm{~mA}$ and $\sim 14 \mathrm{kV}$. The principal limitation of optical CL is that it is a purely qualitative technique that produces a color image of the sample at visible wavelengths $(\sim 400-700 \mathrm{~nm})$. Therefore such studies only allow determination of whether or not the sample luminesces and the dominant wavelength of emission when an electron beam is applied. Supplementary techniques such as Proton Induced X-Ray Emission (PIXE) are required in order to quantitatively interpret the CL image [e.g., Barbin et al., 1995]. Traditional optical CL alone does not provide direct information on the centers responsible for activation of the luminescence.

[6] These drawbacks of conventional optical CL can be overcome with hyperspectral CL imaging. In contrast to cold optical CL, hyperspectral CL imaging offers complete control over the beam conditions applied including beam current, current density and accelerating voltage. The results are wholly quantitative and include the total luminescence emitted. This study uses hyperspectral CL imaging where a $3 \mathrm{D}$ data cube is generated using a full 1024-element CL spectrum at each pixel of the digital image. The data can be reduced to $2 \mathrm{D}$ representations such as spectrally selected intensity maps and real color images. Another advantage of this technique is the capacity to acquire major and trace element chemical analyses by Wavelength Dispersive Spectroscopy (WDS) simultaneously with the CL. Quantification of the trace elements can be achieved using the WDS and the resulting elemental composition images correlated directly with images generated from the hyperspectral CL mapping [Lee et al., 2005; Martin et al., 2004]. This technique therefore offers the opportunity to advance our current understanding of the geochemistry of carbonate shells and the causes of luminescence they display. Additionally, if the conditions that are required to generate a linear change in luminescence intensity can be determined, then it will be possible to draw an accurate correlation between separate studies, something that is not currently possible with optical CL.
[7] The study compares the CL response of a modern Craniid brachiopod, Novocrania anomala with a fossil Craniid brachiopod, Crania craniolaris. Characterization of the modern Craniid is done in the context of a small survey of other modern carbonate shells including another brachiopod, Terebratulina retusa, the bivalve mollusc, Mytilus edulis with its shell of calcite and aragonite and finally, a carbonate shell from a nonmarine environment, the eggshell of the domestic fowl, Gallus gallus.

[8] The mini survey of modern biominerals enables comparison of CL intensities and spectra between the shells, providing data on the range of response to identical electron beam conditions. Crucially, the total intensity of light generated by applying beams of different currents to each sample identifies the range of conditions that yield a linear correlation between beam current and emission intensity without beam damage. The survey also serves to assess the extent to which the CL characteristics of $N$. anomala are shared by other systems and the degree to which the same electron beam settings can be applied to other carbonate biominerals. Having established this baseline, comparisons of the modern and fossil Craniid brachiopod shells using hyperspectral CL imaging can be used to quantitatively assess the extent of postmortem diagenetic alteration. This study demonstrates the potential of hyperspectral CL imaging as a tool for palaeontology and biogeochemistry.

\section{Methods}

[9] Living specimens of $N$. anomala and T. retusa were collected from the Firth of Lorne, Oban, NW Scotland $\left(56^{\circ} 26^{\prime} \mathrm{N}, 5^{\circ} 38^{\prime} \mathrm{W}\right)$. Both species were collected from the same location at a depth of $200 \mathrm{~m}$ where they are associated with a mussel bed of the horse mussel, Modiolus modiolus. $N$. anomala cements its shell to the substrate via its ventral valve while $T$. retusa is attached to the substrate by a pedicle. For both brachiopods, only the dorsal valves of the specimens were used. Specimens of the bivalve M. edulis and G. gallus eggshells were obtained from commercial sources. Fossil specimens of the brachiopod C. craniolaris (Lower Campanian, Cretaceous) were obtained from Ignaberg Quarry, Sweden. As for the modern brachiopods, only the dorsal valve of $C$. craniolaris was used for analysis.

[10] Brachial (dorsal) valves of the brachiopods were embedded in araldite resin, cut and polished to provide a median section through the shell from anterior to posterior. The cut and polished specimens were then coated with carbon, and silver paint was applied to edges of samples in order to minimize the effect of charging upon the samples. A similar process was used for preparation of for the eggshell of $G$. gallus and for the right valve of the $M$. edulis shell. Initial cold optical CL was carried out using a CITL Technosyn 8200 MK4 mounted on a Zeiss Axioplan petrological microscope. Hyperspectral CL imaging used a Cameca SX-100 electron-microprobe equipped with an optical spectrometer capable of acquiring a full 350- to $850-\mathrm{nm}$ emission spectrum at each point in a $2 \mathrm{D}$ scan. CL maps and spectra were extracted from the resultant multidimensional data set using custom designed computer software, Cathodoluminescence Hyperspectral Imaging 

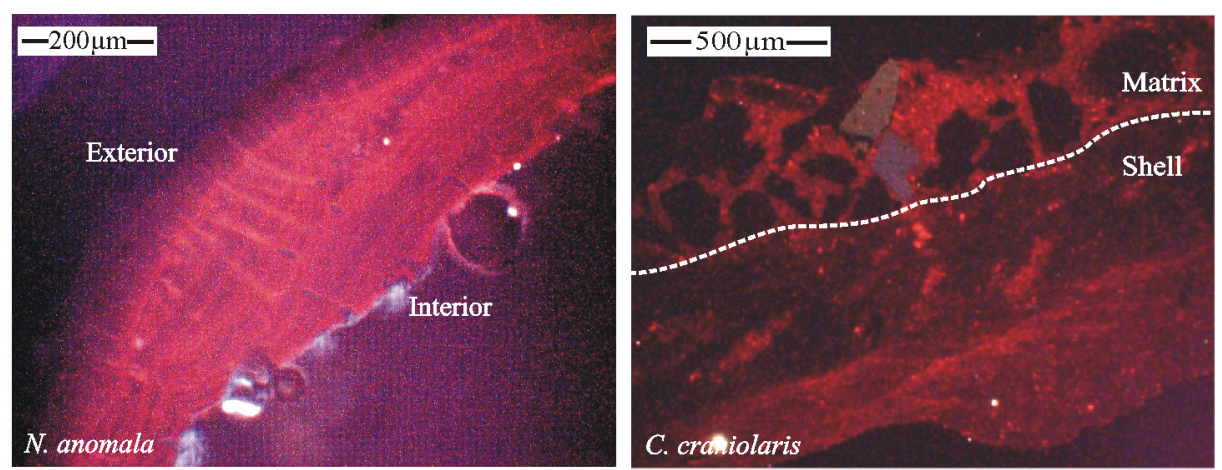

a
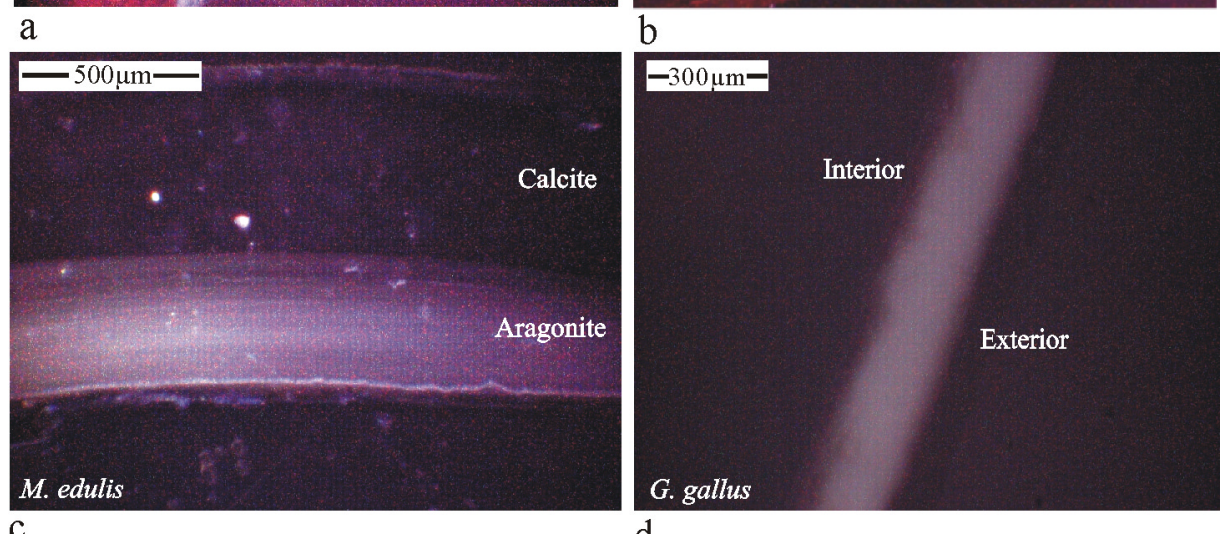

$\mathrm{d}$

Figure 1. Optical CL images of modern and fossil carbonate shells. Images of CL emission from (a) N. anomala, (b) C. craniololaris, (c) M. edulis, and (d) G. gallus acquired by cold optical cathodoluminescence. The exterior and interior walls of the $N$. anomala shell and the eggshell are labeled. In Figure $1 \mathrm{~b}$ the boundary between the outer wall of the fossil shell and the rock matrix is marked by a dashed white line. The outer calcite layer and inner aragonite layer of $M$. edulis are highlighted. Both the modern brachiopod $N$. anomala and the fossil brachiopod C. craniolaris luminesce orange-red. Texture is visible in the shells of both brachiopods. The outer region of the calcite layer and the aragonite layer of M. edulis luminesce white/blue. Variation in luminescence intensity can be seen between layers of aragonite in M. edulis.

and Manipulation Program (CHIMP), (University of Strathclyde, UK).

[11] The shell of M. edulis is different from that of the other carbonate systems in this study in that it is composed of two calcium carbonate polymorphs, aragonite and calcite, which form distinct layers. The calcite and aragonite layers of $M$. edulis were measured separately as these two polymorphs are likely to respond in different ways to the electron beam. The other biominerals are all composed of calcite.

[12] Each specimen was chemically analyzed by electron microprobe and X-ray maps for $\mathrm{Na}, \mathrm{Mg}, \mathrm{Ca}, \mathrm{Mn}, \mathrm{Fe}$ and $\mathrm{Sr}$ were acquired. To establish whether luminescence scales linearly with beam current, the microprobe $\mathrm{CL}$ analyses were carried out at $15 \mathrm{kV}$ with beam currents ranging from 1 to $100 \mathrm{nA}$, and the total intensity of light emitted at each step was recorded. Analyses were carried out at adjacent spots in order to prevent the examination of an area previously damaged by the electron beam.

\section{Results}

\subsection{Optical CL}

[13] Under cold optical CL, T. retusa was non-luminescent whereas both $N$. anomala (Figure 1a) and the fossil
Craniid, C. craniolaris, luminesce orange-red (Figure 1b). The mussel, M. edulis displays a faint luminescence from the outer region of the calcite layer although most of the layer is nonluminescent (Figure 1c). The aragonite layer exhibits white/blue luminescence while the intensity of luminescence varies between individual layers of aragonite nacre. The avian eggshell also luminesces white under cold optical CL (Figure 1d).

\subsection{Modern Carbonate Survey}

[14] Electron beam damage can occur when the crystal lattice becomes charged and heated and begins to break down, resulting in a decrease in total luminescence intensity. In order to express CL emission quantitatively, it is crucial to ensure that beam damage is limited and that the CL emission responds linearly to changes in beam current. Luminescence generated from all four biominerals was assessed using beam currents ranging from 1 to $100 \mathrm{nA}$. The area to which the electron beam was applied ranged from below $1 \mu \mathrm{m}$ (focused beam) to $15 \mu \mathrm{m}$ diameter.

[15] At low beam current (below $50 \mathrm{nA}$ ), T. retusa displays high luminescence intensity. Damage at greater beam currents (50 nA and above) is evident (Figure 2a). CL emission increases linearly up to $50 \mathrm{nA}$ with beam diameters of $<1$ (focused beam), 5 and $10 \mu \mathrm{m}$ (Figure 2a). In 

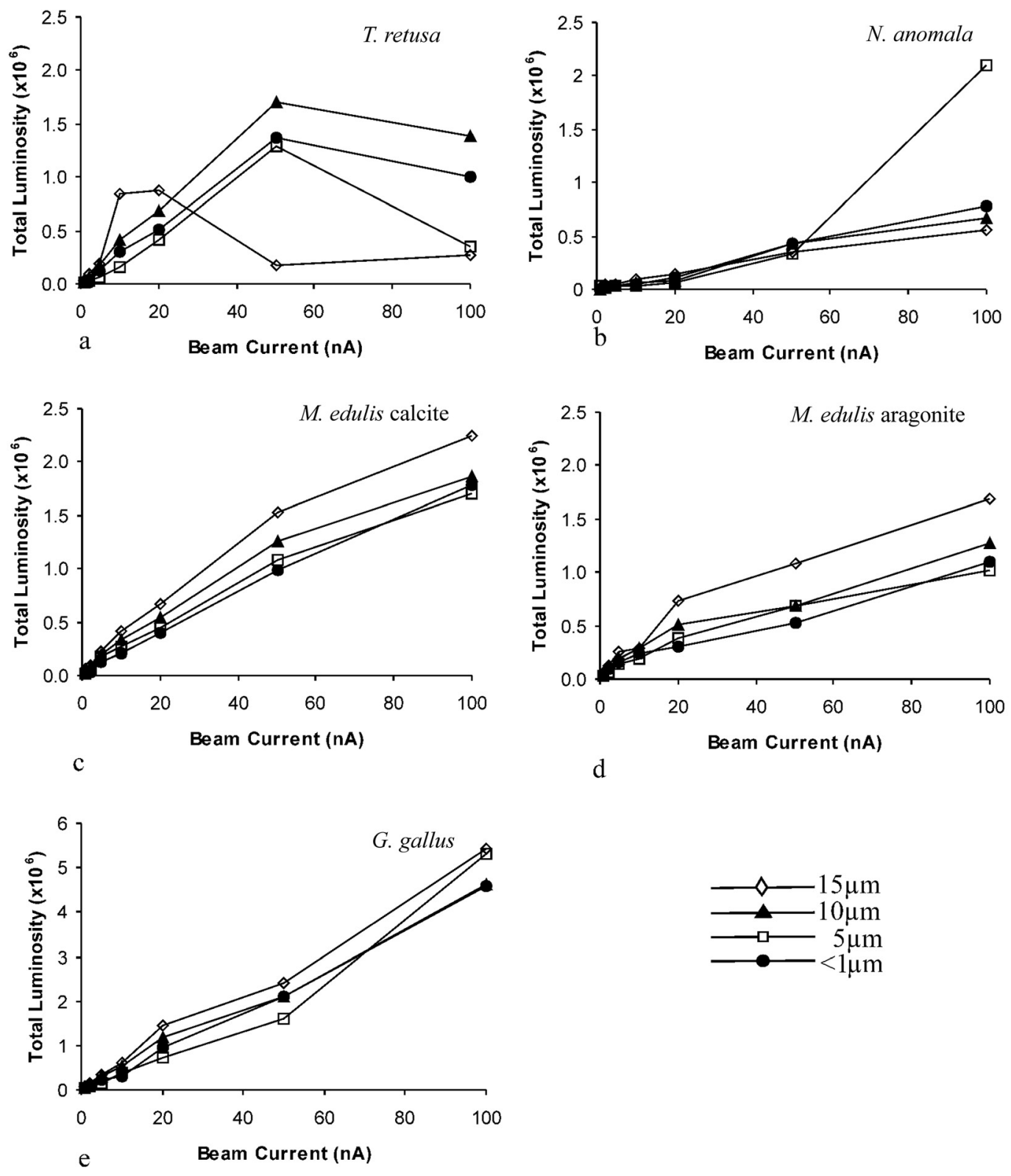

Figure 2. Total intensity of light emitted by modern carbonate biominerals under different beam energies and beam diameters. Total intensity of light emitted by the shells of (a) T. retusa, (b) N. anomala, (c) M. edulis (calcite), (d) M. edulis (aragonite), and (e) G. gallus. CL intensity analyses were carried out on a Cameca SX 100 electron microprobe equipped with a CL spectrometer with a detection range for luminescence wavelengths between 350 and $850 \mathrm{~nm}$. For each specimen luminescence emission increases linearly over the range of $1 \mathrm{nA}$ to $20 \mathrm{nA}$ when applying a focused beam.

T. retusa, maximum CL intensities were achieved with a beam current of $50 \mathrm{nA}$ applied with $10 \mu \mathrm{m}$ diameter. The brachiopod T. retusa luminesces at blue wavelengths (Figure $3 \mathrm{a}$ ).

[16] In $N$. anomala, luminescence intensities increase linearly with beam current. $N$. anomala is less susceptible to beam damage and emits less luminescence than T. retusa (Figure 2b). Maximum luminosity is emitted when a $100 \mathrm{nA}$ beam current is applied with a narrow beam $(<1$ or $5 \mu \mathrm{m}$ diameter). In the outermost region (primary layer) of
$N$. anomala, light from the blue part of the spectrum $(\sim 410 \mathrm{~nm})$ is emitted. In the secondary layer, there is also emission at wavelengths between 620 and $630 \mathrm{~nm}$ resulting in pink/purple luminescence (Figure 3e).

[17] In M. edulis calcite and aragonite, total luminosity emitted is strongly influenced by beam current and diameter (Figures 2c and 2d). In both cases, maximum emission intensities were generated by using a $100 \mathrm{nA}$ current with a $15 \mu \mathrm{m}$ diameter beam (Figures $2 \mathrm{c}$ and $2 \mathrm{~d}$ ). The aragonite 

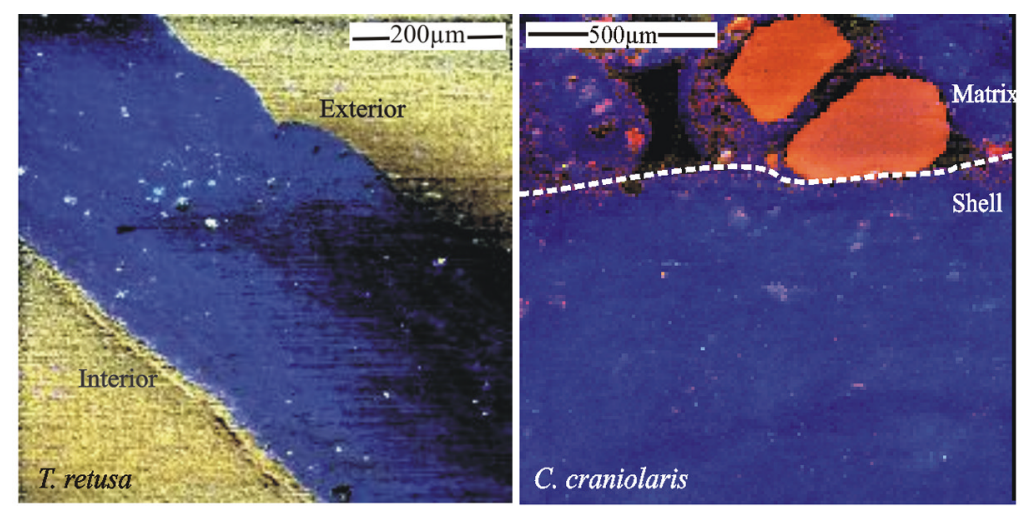

a

$\mathrm{b}$
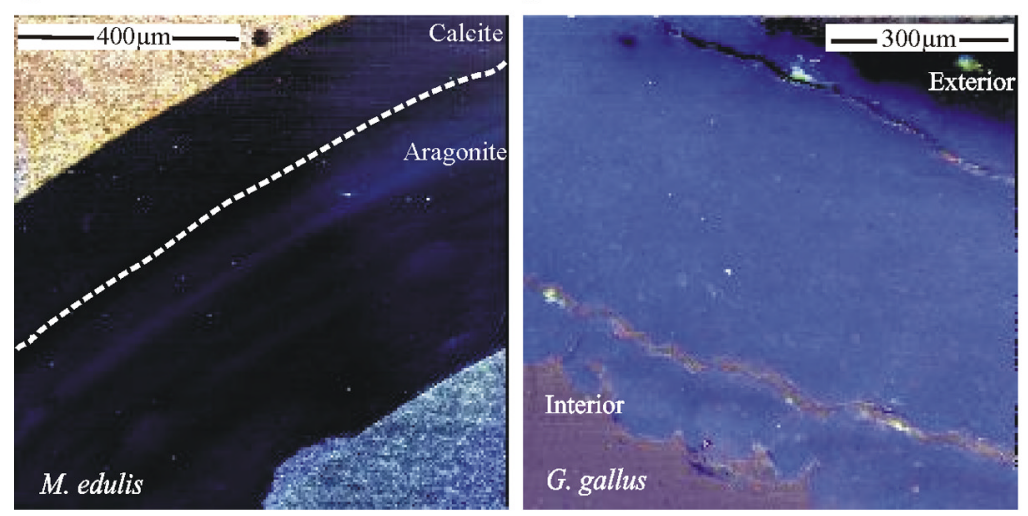

d

$\mathrm{c}$

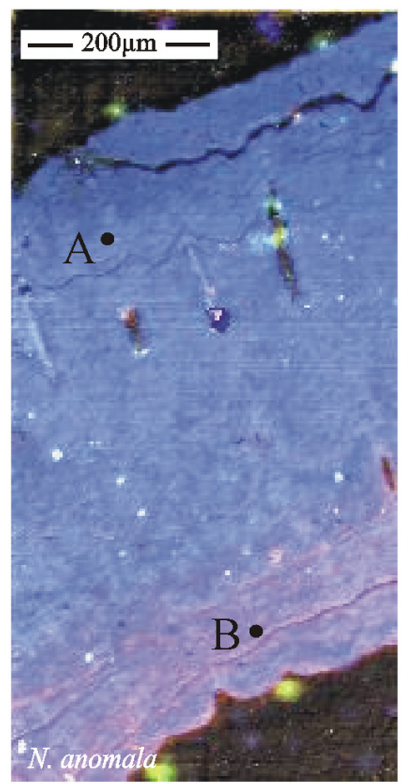

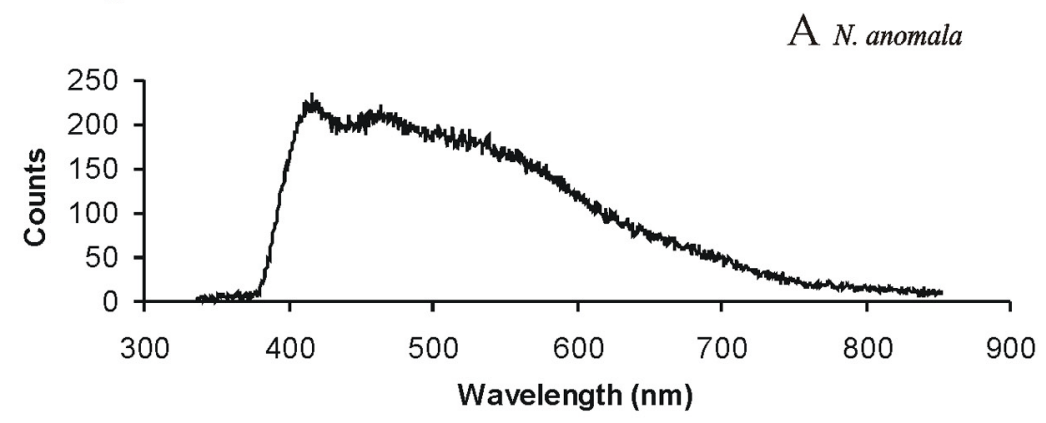

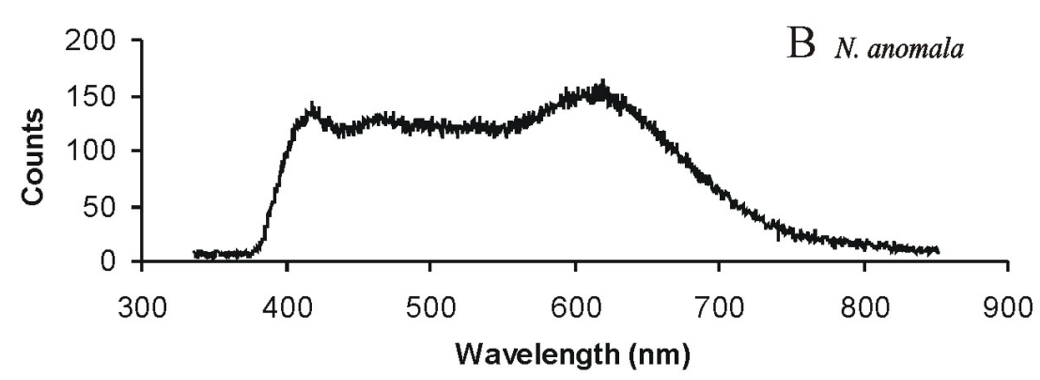

e

Figure 3. Hyperspectral CL images of modern and fossil carbonate biominerals. Hyperspectral CL images of (a) T. retusa, (b) C. craniolaris, (c) M. edulis, (d) G. gallus, and (e) N. anomala with luminescence emission spectra from outer (A) and inner (B) regions of shell. The exterior and interior walls of (Figure 3a) T. retusa and (Figure 3d) G. gallus are indicated. Boundaries between the shell and matrix in (Figure $3 \mathrm{~b}$ ) C. craniolaris and the calcite and aragonite layers of (Figure 3d) M. edulis are marked by a dashed white line. The points at which spectra $\mathrm{A}$ and $\mathrm{B}$ were acquired are marked by black circles.

layer luminesced at lower intensities than the calcite layer. Both M. edulis calcite and aragonite emit blue luminescence. The intensity of luminescence emitted from different layers of the aragonite nacre varies (Figure 3c).
[18] In the eggshell of the domestic fowl, Gallus gallus, luminescence intensities are greater than from any of the marine invertebrates investigated here. Changing the beam diameter has little effect on luminescence in G. gallus 
(Figure 2e). Hyperspectral CL imaging also shows that G. gallus exhibits blue luminescence (Figure 3d). X-ray chemical analysis indicates that the inner shell surface is enriched in magnesium and potassium while calcium, phosphorus, sodium and sulphur occur in higher concentrations in the outer parts of the shell.

\subsection{Fossil Craniid}

[19] Results from the survey of modern carbonate shells described above showed that luminescence emission increased linearly with beam current over the range of $1 \mathrm{nA}$ to $20 \mathrm{nA}$ when using a focused beam. Therefore a focused beam with $10 \mathrm{nA}$ current was used for Hyperspectral CL imaging of the fossil brachiopod C. craniolaris. Once again the results of cold optical and Hyperspectral CL differ. The image obtained by cold optical CL displays pink luminescence and texture within the shell wall is also clearly visible (Figure 1b); however, the hyperspectral CL image suggests that the luminescence emission wavelength is predominantly blue, and while there is still some indication of texture within the shell wall, it is less apparent than in the optical CL image (Figure $3 \mathrm{~b}$ ). The shell itself luminesces blue in contrast to the matrix that encloses the fossil (Figure 3b). When compared to the CL emission from modern carbonate biominerals such as $T$. retusa, which also emits predominantly blue luminescence, there is little evidence to suggest that the shell of $C$. craniolaris is fossilized.

\section{Discussion}

[20] Hyperspectral CL imaging is a new technique that has a number of advantages over traditional optical CL in the study of biogenic carbonates. It is a quantitative technique that also allows for greater control over the beam current applied and the area exposed to the beam. This is important with regard to carbonate materials that are particularly prone to beam damage, which has a detrimental effect on luminescence intensities. Therefore, with the control over beam conditions that hyperspectral CL imaging allows, beam damage to the sample can be avoided. Hyperspectral CL imaging also provides a measure of the total luminescence emitted. When combined with WSD chemical analysis, it is possible to some extent to determine the activator elements present within the shell material which determine luminescence characteristics, for example, manganese in $N$. anomala. In cases where elements are present in concentrations below the detection limit of WDS electron microprobe analysis, hyperspectral CL imaging can detect the luminescence from these elements. This technique is therefore a useful tool for analysis of the chemical composition of both modern and fossil specimens and may provide information on diagenetic processes. Since the causes and constraints of the luminescence of carbonate shells is still poorly understood, the use and development of this technique offers potential for the further advancement of our understanding.

[21] All the modern carbonate shells in this survey predominantly luminesce at blue wavelengths. Blue luminescence is considered to be an intrinsic characteristic of calcite [Marshall, 1988]. The cause of this luminescence is not fully understood; however, Lee et al. [2005] exclude $\mathrm{Fe}^{2+}$ as the sole contributor.
[22] Barbin and Gaspard [1995] reported blue and orange luminescence emission from specimens of T. retusa. In this case, however, the orange luminescent bands described by Barbin and Gaspard [1995] were absent. It has been suggested that the luminescence emitted from the shell may relate to the growth rate of T. retusa [Barbin and Gaspard, 1995]. Indeed in Triassic Rhaetina brachiopods, CL provides evidence of intraspecific and interspecific differences in growth patterns [Tomasovych and Farkas, 2005]. The distribution of elements such as magnesium throughout the shell of T. retusa indicates that growth rate may influence the chemical composition of the shell with the magnesiumrich primary layer of the shell having a faster rate of growth than the magnesium-poor secondary layer [England, 2005; Cusack et al., 2006]. In the present study we found no variation in the wavelength and intensity of luminescence between the primary and secondary layer of $T$. retusa indicating that variations in growth rate in this case are not reflected in the luminescence emission.

[23] Manganese is the main activator element for luminescence in carbonates [e.g., Sommer, 1972; Machel et al., 1991]. In sixfold coordination, $\mathrm{Mn}^{2+}$ has an atomic radius of $0.80 \AA$ compared with $0.99 \AA$ for $\mathrm{Ca}^{2+}$ [Barbin et al., 1995]; therefore $\mathrm{Mn}^{2+}$ can substitute up to $40 \%$ by weight $\mathrm{MnCO}_{3}$ in the calcite lattice [Berry and Mason, 1959]. In the $N$. anomala shell, manganese occurs in higher concentrations, coincident with the occurrence of the pink/purple luminescence (Figure 4). It is possible that the emission at $620-630 \mathrm{~nm}$ alone would result in orange/red optical luminescence more similar to that observed in various brachiopod taxa by Barbin and Gaspard [1995] while the cooccurrence of the additional, sharp emission peak at $\sim 410 \mathrm{~nm}$ results in pink/purple optical luminescence.

[24] Aragonite in the shell of M. edulis emits blue luminescence. The intensity of luminescence varies between layers of aragonite nacre within the shell. This may be attributed to small-scale variations in elemental composition; however, we cannot confirm this from electron microprobe data.

[25] It has been previously suggested that catholuminescence may be affected by other elements including magnesium [Marshall, 1988]. For the four modern carbonate systems discussed here, there is no correlation between luminescence and the concentration of $\mathrm{Mg}, \mathrm{Na}, \mathrm{S}$, and $\mathrm{Sr}$ within the sample. In $T$. retusa, M. edulis and the avian eggshell there are changes in element distribution across the shells that do not correlate with variations in either the wavelength or intensity of luminescence emitted. In the presence of a sufficient concentration of manganese, however, luminescence with a wavelength between 620 and $630 \mathrm{~nm}$ is emitted (Figures 4a and 4b).

[26] The intensity of the luminescence emission differs significantly between the four modern carbonate shells in response to the same conditions. The eggshell displays the highest luminescence intensity of the four shells. The influence of beam damage on luminescence intensity is also apparent in some of the carbonate biominerals assayed and is best illustrated by $T$. retusa (Figure 2a).

[27] These characteristics may be attributed to the fundamental differences in the shell structure of the different systems [Cusack and Williams, 2001], and serves to highlight the importance of the control of parameters such as beam 


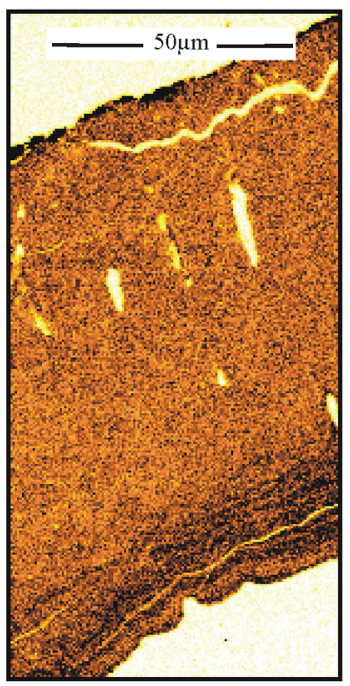

a

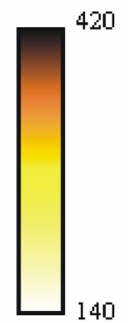

140

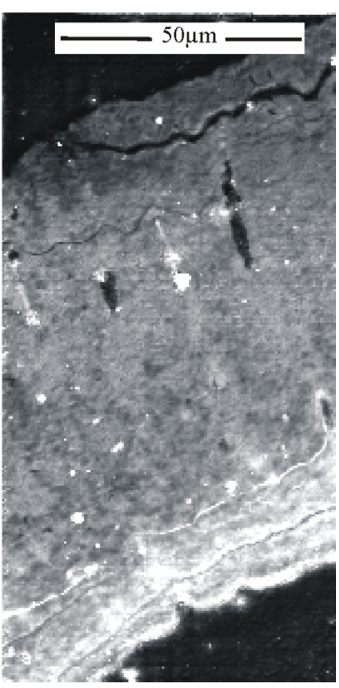

b
Figure 4. (a) Wavelength dispersive map of manganese concentration in $N$. anomala. (b) Map of luminescence emission of wavelengths between $620-630 \mathrm{~nm}$ emitted by $N$. anomala. Areas of high manganese concentration correspond to dark/black regions of the $\mathrm{Mn}$ map. The luminescence map displays the emission of luminescence with a wavelength between 620 and $630 \mathrm{~nm}$. Lighter areas (white/light-gray areas) on the luminescence map correspond to regions where the intensity of luminescence between 620 and $630 \mathrm{~nm}$ wavelength is greatest. Dark regions (black/dark-gray areas) of the luminescence map correspond to regions where the intensity of luminescence between 620 and $630 \mathrm{~nm}$ wavelength is lowest. Areas of high manganese concentration in the shell of $N$. anomala correspond to areas of the shell from which the intensity of luminescence (620- to 630-nm wavelength) is greatest.

current and beam diameter in such studies, a factor which is fundamentally absent in conventional cold optical CL.

[28] The results of this initial study show the power of this technique and the implications it will have in future studies. Not only will it have important applications in palaeontology, palaeoclimatology and biogeochemistry, but also in petroleum exploration in assessing the diagenetic alteration of reservoir rocks [Lee et al., 2005].

[29] Acknowledgments. The authors thank the crew of the R/V Calanus for their help in collecting T. retusa and $N$. anomala specimens. John Gilleece is thanked for preparing the polished blocks, and Robert McDonald is thanked for help with microprobe analyses. M. C. and J. E. are grateful to the EPSRC (GR/R23107/01) for supporting this research. The Synergy Fund and John Robertson Bequest (JR04/17) of Glasgow University are thanked for financial support (M. C., M. R. L., and N. P.). The authors would also like to thank the Carnegie Trust for the Universities of Scotland for financial assistance for color publishing. Fossil brachiopods were provided by the late Sir Alwyn Williams. We thank Robert M. Reed, Erika Griesshaber, and an anonymous reviewer for their comments which improved this manuscript.

\section{References}

Auclair, A. C., M. M. Joachimski, and C. Lecuyer (2003), Deciphering kinetic, metabolic and environmental controls on stable isotope fractionations between seawater and the shell of Terebratalia transversa (Brachiopoda), Chem. Geol., 202, 59-78.

Banjeree, A., and A. Habermann (2000), Identification of Chinese freshwater pearls using $\mathrm{Mn}^{2+}$ activated cathodoluminescence, Carbonates Evaporites, 15, 138-148.
Barbin, V. (1991), Strie de crossance révélées par cathodoluminescence dans la coquille de Pecten maximus récent de la rade de Brest (Pectinidae, Bivalvia), Geobios, 24, 65-70.

Barbin, V. (1992), Fluctuation in shell composition in Nautilus (Cephalopoda, Mollusca): Evidence from cathodoluminescence, Lethaia, 25 , $391-400$.

Barbin, V., and D. Gaspard (1995), Cathodoluminescence of recent articulate brachiopod shells: Implications for growth stages and diagenesis evaluation, Geobios, 18, 39-45.

Barbin, V., K. Ramseyer, J. P. Debenay, E. Schein, M. Roux, and D. Decrouez (1991), Cathodoluminescence of recent biogenic carbonates: An environmental and ontogenetic fingerprint, Geol. Mag., 128(1), 1926.

Barbin, V., U. Brand, R. A. Hewitt, and K. Ramseyer (1995), Similarity in cephalopod biochemistry since carboniferous: Evidence from cathodoluminescence, Geobios, 28, 701-710.

Berry, L. G., and B. Mason (1959), Mineralogy: Concepts, Descriptions, Determinations, 612 pp., W. H. Freeman, New York.

Budd, D. A., U. Hammes, and B. Ward (2000), Cathodoluminescence in calcite cements: New insights on $\mathrm{Pb}$ and $\mathrm{Zn}$ sensitizing, Mn activation, and $\mathrm{Fe}$ quenching at low trace element concentrations, J. Sediment. Res., $70,217-226$.

Cusack, M., and A. Williams (2001), Evolutionary and diagenetic changes in the chemico-structure of the shell of the cranioid brachiopods, Palaeontology, 44, 875-903.

Cusack, M., J. England, D. Parkinson, P. Dalbeck, M. Lee, G. Curry, and A. E. Fallick (2006), Oxygen isotope composition, magnesium distribution and crystallography of Terebratulina retusa, Fossils Strata, in press. Czerniakowski, L. A., K. Lohmann, and J. L. Wilson (1984), Closedsystem marine burial diagenesis: Isotopic data from the Austin Chalk and its components, Sedimentology, 38, 863-877.

England, J. (2005), Calcium carbonate biomineralisation in disparate systems - Common mechanisms?, Ph.D. thesis, 157 pp., Univ. of Glasgow, Glasgow, U. K.

Friedman, G. M. (1993), Discussion of cathodoluminescence of recent biogenic carbonates: An environmental and ontogenetic fingerprint, Geol. Mag., 130, 269-279.

Korte, C., H. W. Kozur, and J. Veizer (2003), Strontium isotope evolution of late Permian and Triassic seawater, Geochim. Cosmochim. Acta, 67, 47-62.

Korte, C., T. Jasper, H. W. Kozur, and J. Veizer $(2005), \delta^{18} \mathrm{O}$ and $\delta^{13} \mathrm{C}$ of Permian brachiopods: A record of seawater evolution and continental glaciation, Palaeogeogr. Palaeoeclimatol. Palaeoecol., 224, 333-351.

Lee, M. R., R. W. Martin, C. Trager-Cowan, and P. Edwards (2005), Imaging of cathodoluminescence in calcite by scanning electron microscopy and hyperspectral mapping, J. Sediment. Res., 75, 313-322.

Machel, H. G., R. A. Mason, A. N. Mariano, and A. Mucci (1991), Causes and emission of luminescence from dolomite, in Luminescence Microscopy: Quantitative and Qualitative Aspects, Short Course Notes, vol. 25, edited by C. E. Barker and O. C. Kopp, pp. 149-154, Soc. of Econ. Palaeontol. and Mineral., Tulsa, Okla.

Marshall, D. J. (1988), Cathodoluminescence of Geological Material, 146 pp., CRC Press, Boca Raton, Fla.

Martin, R. W., P. R. Edwards, K. P. O'Donnell, M. D. Dawson, C. W. Jeon, C. Liu, G. R. Rice, and I. M. Watson (2004), Cathodoluminescence spectral mapping of III-nitride structures, Phys. Status Solidi A, 201, $665-672$.

Middleton, P. D., J. D. Marshall, and P. J. Brenchley (1991), Evidence for isotopic change associated with Late Ordovician glaciation from brachiopods and marine cements of central Sweden, Pap. Geol. Surv. Can., 90, $313-321$.

Parkinson, D., G. B. Curry, M. Cusack, and A. E. Fallick (2005), Shell structure, patterns and trends of oxygen and carbon stable isotopes in modern brachiopod shells, Chem. Geol., 219, 193-235.

Popp, B. N., F. A. Podosek, J. C. Brannon, T. F. Anderson, and J. Pier (1986), ${ }^{87} \mathrm{Sr} /{ }^{86} \mathrm{Sr}$ Ratios in Permo-Carboniferous seawater from the analyses of well preserved brachiopod shells, Geochim. Cosmochim. Acta, 50, $1321-1328$.

Ramseyer, K., J. Fischer, A. Matter, P. Eberhardt, and J. Geiss (1989), A cathodoluminescence microscope for low intensity luminescence, J. Sediment. Petrol., 59, 619-622.

Rush, P. F., and H. S. Chafetz (1990), Fabric retentive, non-luminescent brachiopods as indicators of original ${ }^{813} \mathrm{C}$ and ${ }^{818} \mathrm{O}$ composition: A test, J. Sediment. Petrol., 60, 968-981.

Samtleben, C., A. Munnecke, T. Bickert, and J. Patzold (2001), Shell succession, assemblage and species dependant effects on the C/O-isotopic composition of brachiopods-examples from the Silurian of Gotland, Chem. Geol., 175, 61-107.

Schein, E., M. Roux, V. Barbin, F. Cheisi, M. Renard, and M. Rio (1991), Enregistrement des parametrés écologiques par la coquille 
des bivalves; approche plundisciplinaire, Bull. Soc. Geol. Fr., 162, 687-698.

Sommer, S. E. (1972), Cathodoluminescence of carbonates: 2. Geological applications, Chem. Geol., 9, 275-284.

Stueber, T., and M. Rauch (2005), Evolution of the $\mathrm{Mg} / \mathrm{Ca}$ ratio of Cretaceous seawater: Implications from the composition of biological low $\mathrm{Mg}$ calcite, Mar. Geol., 217, 199-213.

Tomasovych, A., and J. Farkas (2005), Cathodoluminescence of Late Triassic terebratulid brachiopods: Implications for growth patterns, Palaeogeogr. Palaeoclimatol. Palaeoecol., 216, 215-233.
Veizer, J., et al. (1999), ${ }^{87} \mathrm{Sr} /{ }^{86} \mathrm{Sr}, \delta^{13} \mathrm{C}$ and $\delta^{18} \mathrm{O}$ evolution of Phanerozoic seawater, Chem. Geol., 161, 59-88.

M. Cusack, J. England, M. R. Lee, and N. W. Paterson, Department of Geographical and Earth Sciences, Gregory Building, Lilybank Gardens, University of Glasgow, Glasgow G12 8QQ, UK. (j.england@ges.gla.ac.uk)

P. Edwards and R. Martin, Department of Physics, University of Strathclyde, John Anderson Building, 107 Rottenrow, Glasgow G4 0NG, UK. (paul.edwards@strath.ac.uk) 